\title{
Psychological Hardiness among Undergarduate Students
}

\author{
Rabiya Rasool ${ }^{1}$
}

\author{
Research Scholar, School of Education, Central University of Kashmir, India \\ Email: rabiya9rasool@gmail.com
}

DOI $<10.26821 / I J S R C .8 .10 .2020 .8905>$

\begin{abstract}
The investigator in the present study compared psychological hardiness between male and female undergraduate students. The sample of the study includes 120 stduents selected from different colleges of district Srinagar using simple random sampling technique. The researcher used self-construted and standardized tool for the study. The data was analysed by applying the t-test. The results revealed that significant difference existed between male and female undergraduate students on psychological hardiness and female students possess high psychological hardiness.
\end{abstract}

Keywords: Psychological Hardiness; Undegraduate Students; College Students.

\section{Introduction}

The concept of hardiness was introduced byKobasa (1979), who defined it "as a resistance resource in the encounter with stressful situations". It is a pattern of personality characteristics comprisedof three related dispositions - commitment, control, and challenge. Control is defined as the ability of a person to influence the life happenings through one's own effort. Commitment refers to the ability of a person to show willingnessto work hard and are curious about the people, things and activities, while as Challenge refers to the ability of a person to face the stressful life situations that provide opportunities for personal growth.

Individuals with high hardiness influence the end results of the life without considering the positivity or negativity, are actively involved in theactivities of life and learning out of it. On the other hand, "individuals low on hardiness will be more likely to withdraw from some life circumstances and perceive them as more threatening"(Maddi, 1999).Hardiness is considered as a protective construct in depressive situations mostly through cognitive appraisal and coping behaviors. Sheard, 2009 concluded that psychological hardiness plays an important part in the life of a person. While conducting his research he revealed that females possess high psychological hardiness than males."Persons with high hardiness approach life actively and perceive that they can handle them successfully, view them as meaningful and useful, which results in less stressful experience"(Maddi, 1990). Hardiness as a protective function could be found in its effect on the decision of the circumstances that one will be engaged with. The impact of hardiness on cognitive appraisal and coping efforts refer only to the individual differences in the reactions to actual stressful situations. Despite the fact that, hardiness does not effect only the actual stressful situations, insteadexamines the past experience, benefits of various behaviors, and therefore, the choice of important, meaningful and challenging situations. Thus, "hardiness does not influence only the reactions to the stressful stimuli, but can also lead to qualitatively different experiences"(Wiebe \& Williams, 1992).

The investigator conducted this study in that part of the world which is in turmoil since three decades. Conflict has now become part of life and people are used to this despite the fact that it has affected them physically, emotional, mentally and socially. So the investigator conducted the study on students enrolled in the colleges to see their optimistic attitude towards life irrespective of turmoil.

Objective 
Volume 8 Issue 10 October 2020

To compare psychological hardiness between male and female undergraduate students.

\section{Hypothesis}

There is no significant difference between male and female undergraduate students on psychological hardiness.

\section{Operational Definition of Variable}

\section{Psychological Hardiness:}

Psychological Hardiness is defined as the combination of personality traits that help an individual to overcome the stress and see life optimistically. It includes commitment, control, challenge, self-confidence and lifeacceptance. In the present study, psychological hardiness has been defined as the scores obtained on the psychological hardiness scale.

\section{Methodology}

\section{Sample}

The investigator has selected 120 (60 male and 60 female) undergraduate students from colleges of district Srinagar through random sampling technique.

\section{Tools used}

The investigator constructed and standardized her own scale for measuring psychological hardiness. After literature review and expert opinion, the researcher selected five personality traits viz. commitment, control, challenge, self-confidence and life-acceptance for defining psychological hardiness. Exploratory factor analysis and confirmatory factor analysis has been employed to standardize the scale. The sample adequacy was measured by KMO (Kaiser-Meyer-Olkin) which was calculated to be .706 and Bartlett's test has been found to be significant $(\mathrm{p}=.000)$. The EFA results showed that Communalities of the items ranged from .565 to .986 and the item loading ranged from .569 to .980 . Further, the results revealed that Psychological Hardiness Scale decomposed into 5 factors consisting of 29 items which accounted for $79.18 \%$ of variance.

After EFA, the stability of items has been confirmed through Confirmatory Factor Analysis (CFA) with the help of AMOS 20 and the results revealed that the different indices are good fit for the model.

Table 01:Showing different good fit indices of the scale

\begin{tabular}{|c|c|c|c|c|c|}
\hline CMIN/DF & RMR & GFI & AGFI & CFI & RMSEA \\
\hline 2.44 & .070 & .850 & .800 & .902 & .070. \\
\hline
\end{tabular}

Although, GFI and AGFI are below .90 but are acceptable.

\section{Reliability and Validity}

Reliability of the scale has been calculated by Cronbach Alpha. The reliability of coefficient for the items ranged from .856 to .465 indicating good reliability. Content Validity of the scale has been established at the time of drafting of the items and has been calculated by Lawshe (1979) method.The formula for calculating CVR is $\left\{\text { CVR }=\frac{\mathrm{Ne}-\mathrm{N} / 2}{\mathrm{~N} / 2}\right\}^{2}$.

\footnotetext{
${ }^{2}\left\{C V R=\frac{N e-N / 2}{N / 2}\right\}$.
} 


\section{Technique used}

The investigator has applied t-test for obtaining the results

\section{Analysis, Interpretation and Discussion}

Table 02: Showing comparison of male and female undergraduate students on Psychological Hardiness. $(\mathbf{N}=120)$

\begin{tabular}{|c|c|c|c|c|}
\hline S. No. & Dimensions & Gender & Mean & t-test \\
\hline \multirow{2}{*}{1.} & \multirow{2}{*}{ Commitment } & Female & 20.90 & \multirow{2}{*}{$3.09^{* *}$} \\
\hline & & Male & 19.00 & \\
\hline \multirow{2}{*}{2.} & \multirow{2}{*}{ Control } & Female & 20.42 & \multirow{2}{*}{1.95} \\
\hline & & Male & 19.07 & \\
\hline \multirow{2}{*}{3.} & \multirow{2}{*}{ Challenge } & Female & 22.38 & \multirow{2}{*}{$2.90^{* *}$} \\
\hline & & Male & 19.98 & \\
\hline \multirow{2}{*}{4.} & \multirow{2}{*}{ Self-Confidence } & Female & 16.77 & \multirow{2}{*}{1.50} \\
\hline & & Male & 15.77 & \\
\hline \multirow{4}{*}{5.} & \multirow{2}{*}{ Life-Acceptance } & Female & 16.50 & \multirow{2}{*}{0.97} \\
\hline & & Male & 10.01 & \\
\hline & \multirow{2}{*}{$\begin{array}{c}\text { Psychological } \\
\text { Hardiness (Total) }\end{array}$} & Female & 96.97 & \multirow{2}{*}{$2.54^{\star}$} \\
\hline & & Male & 90.88 & \\
\hline
\end{tabular}

**: Significant at 0.01 ; : Significant at 0.05

The Table 02depicts the mean comparison of male and female undergraduate students on various dimensions of psychological hardiness. The table reveals that on commitment dimension of psychological hardiness, female undergraduate students posses high mean value $(M=20.90)$ as compared to male students $(M=19.00)$. The the $t-$ value which comes out to be 3.09 is significant at 0.01 level $(>2.58)$. on control dimension of psychological hardiness, female undergraduate students exhibit mean value $(\mathrm{M}=20.42)$ and male students have mean value of $(\mathrm{M}=19.07)$. the obtained $\mathrm{t}$-value comes out to be 1.95 which is insignificant. The perusal of the table reveals that there is a significant difference between male and female undergraduate students. The mean value of male students is $M=22.38$ and mean value for female students is $M=19.98$. the calculated $t$-value which comes out to be 2.90 is significant at 0.01 level. Moreover, the table reveals that there is insignificant difference between male $(\mathrm{M}=16.77)$ and female $(\mathrm{M}=15.77)$ undergraduate students on self-confidence dimension of psychological hardiness. The table further reveals that there is insignificant difference between amle and female undergraduate students. On composite score of psychological hardiness, the table reveals that there is a significant dufference between male and female undergraduate students. The mean value for male students is $M=90.88$ and mean value for female students is $M=96.97$. the mean value indicates that females exhibit high psychological hardiness then male undergraduate students.

\section{Discussion of the Results}

The results revealed that female undergraduate students exhibit high psychological hardiness than male students. The results reveal that female students possess high commitment towards their work and have self-confidence. Female students are highly ambitious and are willing to achieve their goal. They work hard to make their dreams come true. Further, they see life full of opportunities. Their parents provide full support in realization of their dreams. Even though with the continuous turmoil, the students are very optimistic and goal oriented. On control, challenge and life-acceptance dimension both male and female students are neutral. The results are in line with the findings of the study done by Sheard (2010) and concluded that females possess high psychological

(Ne is No. of experts who consider item appropriate and N is total No. of experts). 
Volume 8 Issue 10 October 2020

hardiness than males.Wang and Miao (2009)reveals that "men and women are having different aspects of health because of different resources and facilities available for each genderthus having different health situations". While the study which contradicts the findings is by Desai (2017)which revealedthat "male students possess more psychological hardiness than women becausemen are less excited in problematic situations and act more reasonably, but women have more excitements". Further, other studies such as Hosseinpour et al. (2008)explained no significant difference between the genders. Thus the objective which states that, "to compare the psychological hardiness between male nad female undergraduate students" has been realized and the hypothesis which reads as, "there is no significant difference between male and female undergraduate students on psychological hardiness" has been partially rejected and tested therof.

\section{Conclusion}

The study revealed that female students exhibit high psychological hardiness than male students except control, challenge and life-acceptance dimensions of psychological hardiness. There is a need to investigate factors that can predict psychological hardiness and to find out the reasons as to why male students have low psychological hardiness than female students because conflict effects both the genders.

\section{Educational Implications}

a) There is a need to develop friendly environment at college as well as home so that students feel free to express themselves.

b) They shoulddevelop relationship skills so that they find themselves attached with peer, friends, faculty etc.

c) There is a need of organizing workshops for such students who are weak, depressed as to how to using coping statragies and skills in overcoming the problems in educational settings or social settings. But, these workshops should be organized by the professionals who are expert in identifying the problems in the students.

\section{References}

Desai Rahul B. (2017). Psychological Hardiness ąmong College Students. The International Journal of Indian Psychology. Volume 4, Issue 3, No. 103, 2017.

Kobasa, S.C. (1979). Stressful life events, Personality, and Health: An inquiry into Hardiness. Journal of Personality and Social Psychology, 37, 1-11.

Maddi, S.R. (1990). Issues and Interventions in Stress Mastery. In H.S. Friedman (Ed.), Personality and Disease (pp. 121-154). New York: Wiley.

Maddi, S.R. (1999). Comments on Trends in Hardiness Research and Theorizing. Consulting Psychology Journal, 51, 67-71.

Sheard, M. (2010). Hardiness Commitment, Gender and Age: Differentiate University Academic Performance. British Journal of Educational Psychology, Vol. 79, Issue 1.

Wang, W and Miao, D. (2009). The relationship among Coping Styles, Personality Traits and Mental Health of Chinese Medical Students. Social Behaviour and Personality: An International Journal, 37(2): 163-172.

Wiebe, D.J., \& Williams, P.G. (1992). Hardiness and health: A Social Psychophysiological Perspective on Stress and Adaptation. Journal of Social and Clinical Psychology, 11, 238-262. 